\title{
An Energy-Economy Model for Indonesia Considering Inter-Regional Energy Resources Transportation and Daily Demand Changes
}

\author{
Saki Yokohama, Utomo Sarjono Putro, Satoshi Ohnishi, and Shunsuke Mori
}

\begin{abstract}
Energy demand in Indonesia is rapidly increasing because of high economic growth. Even if fossil fuel resources in Indonesia is rich, utilization of renewable energy resources is also needed to meet the carbon dioxide emission target by $29 \%$ compared to BAU by 2030 according to the Paris Agreement. Renewable energy sources are expected to provide small-scale distributed power, particularly to improve the electrification of remote or isolated areas. The economic development plannings of regions should also be established considering the regional conditions as well as the energy planning. To accurately evaluate the potentials of intermittent renewable energy such as solar power, hourly changes in demand should be implemented in the energy-economy model explicitly. The purpose of this study is to evaluate the future regional energy use in Indonesia by developing a multiregional energy-economy model considering inter-regional energy resources transportation and daily power load estimating some regional data. The simulation results demonstrate how the development and the environmental policy affect the future energy plannings.
\end{abstract}

Index Terms-Multi-regional energy economy model, energy supply and demand, inter-regional energy transportation, intermittent renewable energy.

\section{INTRODUCTION}

As a new international framework for the reduction of greenhouse gas emission from 2020 which replaces the Kyoto Protocol, the Paris Agreement was adopted at COP21 on the 12th of December 2015. Under the Kyoto Protocol, only developed countries were obliged to reduce greenhouse gas emission, whereas under the Paris Agreement, all the nations including developing countries are obliged to submit and renew the target of reduction every five years. Indonesia, a developing country, set a target in the INDC that it will reduce the emissions of greenhouse gas and short-lived climate pollutants by $29 \%$ compared to BAU by 2030 [1]

Indonesia is an emerging country with the world's fourth largest population. Having been a domestic demand-dependent economy, or a less dependent economy on foreign trade, it was largely unaffected by the global financial crisis in 2007 and the average annual growth rate from 2007 to 2012 was strong, about 6\% [2]. However, the growth rate began to gradually decrease and had fallen below

Manuscript received December 9, 2016; revised May 17, 2017.

Saki Yokohama, Satoshi Ohnishi, and Shunsuke Mori are with the Department of Industrial Administration, Graduate School of Science and Technology, Tokyo University of Sciences, Japan (e-mail: sakiyokohama@gmail.com, ohnishi-s@rs.tus.ac.jp, mori@ia.noda.tus.ac.jp).

Utomo Sarjono Putro is with the School of Business and Management, Institut Teknologi Bandung, Indonesia (e-mail: utomo@sbm-itb.ac.id).
$5 \%$ in 2015 . The basis of potential of growth of Indonesia lies in its rich natural resources and the increase of consumption and production age population, however, power shortage has been obstructing the corporate activities in the country. In recent years, as the consumption of energy, mainly electric power, is rapidly increasing, development of new power source and energy resources is becoming urgently needed. Especially, renewable energy including water power, solar power, wind power, geothermal heat and biomass power generation is highly expected as resources that never exhaust and are of less environmental load. Indonesia has been rich in fossil fuel resources and the energy price has been kept low by subsidy policy, resulting in the low prevalence of renewable energy. But to achieve the goal of reduction of greenhouse gas emission, further prevalence of renewable energy is needed.

Indonesia consists of many islands and the population, economic condition, collectable fossil fuel resources and the potential of the use of renewable energy largely differ from each island to island. Therefore, the prevalence of renewable energy has to be considered on the assumption of having inter-regional energy transportation.

\section{PRIOR RESEARCHES AND PURPOSE}

An Integrated model is one of the most useful methods to evaluate regional energy use, inter-regional energy resources transportation, the influence of energy mix on future economy. Retno et al. (2010) built an integrated model for the low carbon society till 2050 including economy, energy and carbon dioxide emissions [3]. Mori (1994) developed an integrated model for the evaluation of global environment which is called MARIA (Multiregional Approach for Resource and industry Allocation) to analyze future energy mix [4]. Sugiyono (1994) built an Indonesian energy economy model by applying MARIA model to domestic cases of Indonesia, however, large-scaled introduction of renewable energy is not considered [5]. Moreover, as he used yearly data for electric power demand, an accurate evaluation for the introduction of renewable energy that intermittently generates electricity such as solar or wind power was not conducted. To accurately evaluate the introduction of solar power generation, daily changes in demand have to be considered.

As Indonesian economy is expected to continue to grow, the differences in resources, industries and economic levels among regions have to be considered. Options for considerations such as following emerge. If the low carbonization has to be done in the manufacturing industry 
region, energy saving and high optimization of thermal power generation has to be considered whereas in agricultural region, utilization of biomass has to be considered. The focus of low carbonization being high optimization of energy saving or thermal power generation in the industrial region that mainly depend on fossil fuel resources or the use of biomass in the region main industry is farming. Thus, the purpose of this study is to evaluate the future regional energy use in Indonesia by applying an energy-economy model, considering inter-regional energy resources transportation and daily power load.

\section{Methodology}

\section{A. Energy-Economy Flow}

Each region has an energy flow as shown in Fig. 1. Y in Fig 1 is composed of $\mathrm{K}$ (Capital), $\mathrm{L}$ (Population), $\mathrm{E}$ (Electricity) and N(Non-Electricity) and represents a production function. TOT, which is the sum of PRO (Energy production in the region), TRE_F (Energy import) and TRE_D (Domestic energy transportation), represents total energy supply in each region and arrows indicate fuel transportation between regions. Real energy flow is represented by a complex network of all relevant energy technologies interconnected by energy flow from the supply side to the demand side.

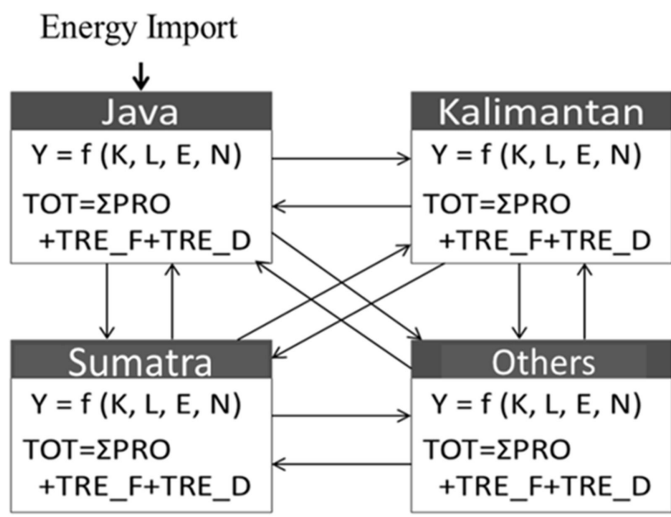

Fig. 1. Block diagram of the regionalized model.

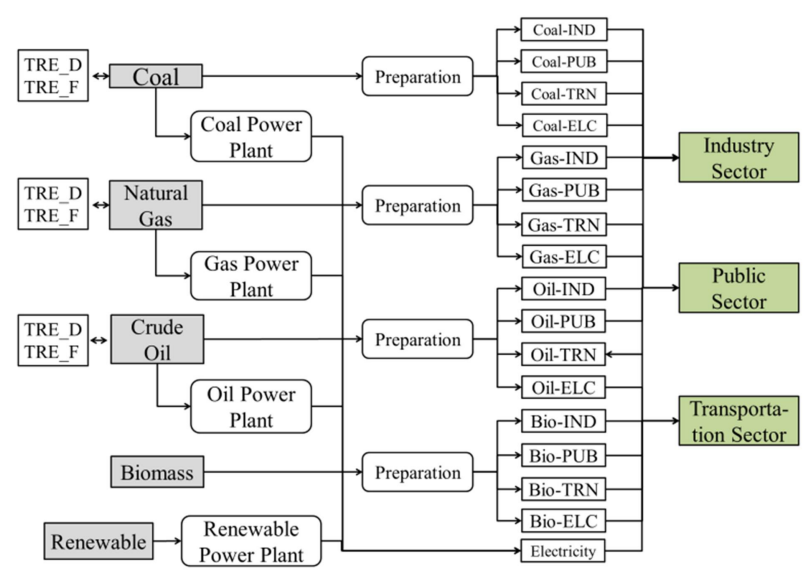

Fig. 2. Structure of regional energy flow model.

In this study, we used an aggregate energy flow to avoid the complexity of the model. The model contains eight primary energy sources: coal, natural gas, crude oil, biomass, hydro power, geothermal power, solar power, and wind power. The energy demand sector is disaggregated into three sectors: industry, public and transportation. Each region has an energy flow as shown in Fig. 2. The individual regions are linked in the model by inter-regional flows such as coal, crude oil and natural gas shipping, but no migration of labor or population was assumed. Fig. 3 shows the paths through which primary energy is converted into secondary energy and consumed in each demand sector as final energy demand. Fossil fuels are distributed to non-electric and electric energy and then allocated to each sector. Fossil fuels are also distributed to non-electric power, and electric energy is supplied to sectors. Renewable energy is only supplied to each sector as electric energy.

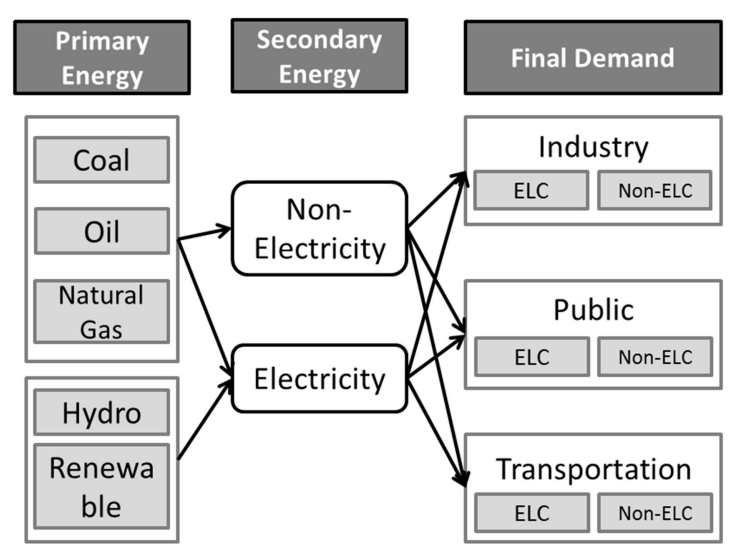

Fig. 3. Energy flow.

\section{B. Study Area}

Indonesia is an archipelagic island country in South-east Asia, lying between the Indian Ocean and the Pacific Ocean. The country consists of main islands such as Java, Sumatra and Kalimantan, and about 17,000 islands. Its total area is $1,919,317 \mathrm{~km}^{2}$. Economic and environmental conditions vary considerably by region. About $50 \%$ of Indonesia's entire GDP originates in six provinces, including the Special Capital Territory of Jakarta on the island of Java. For the study, we divided Indonesia into four regions as the study regions: Java, Sumatra, Kalimantan, and other islands (Fig. 4).

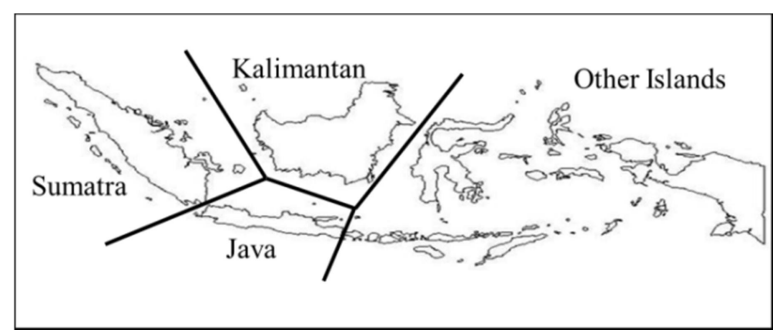

Fig. 4. Indonesia and regional divisions of the model.

\section{Data Estimation}

To construct the energy-economy model in this study, basic regional GDP data, energy demand data, energy supply data, and resource reserve data were necessary. Although these data are available for Indonesia as a whole, there are no published regional data. Therefore, it was necessary to estimate the regional data.

In the following tables and figures, Java, Sumatra, Kalimantan, and other islands are denoted as RG1, RG2, 
RG3, and RG4, respectively.

\section{1) Population and GDP}

Fig. 5 shows each region's population estimation of every five years for eight periods, 2010-2045. Based on Indonesia's future population projection by the United Nations, it was determined by regional data from Statistics Indonesia [6] and Citypopulation [7]. GDP data of each region in 2010 was obtained from World Bank [8] and Statista [9] (Fig. 6).

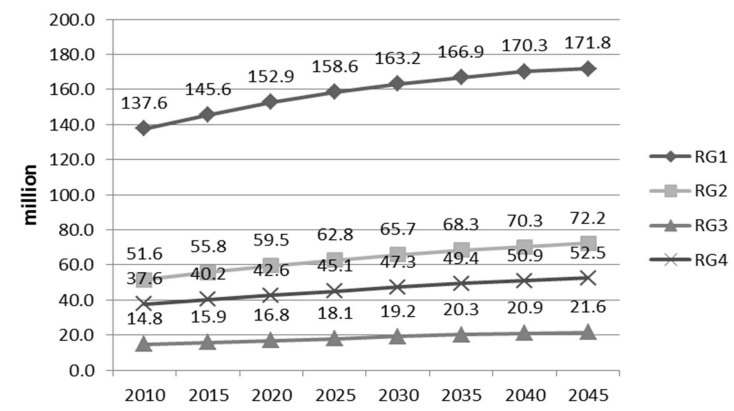

Fig. 5. Population of Indonesia.

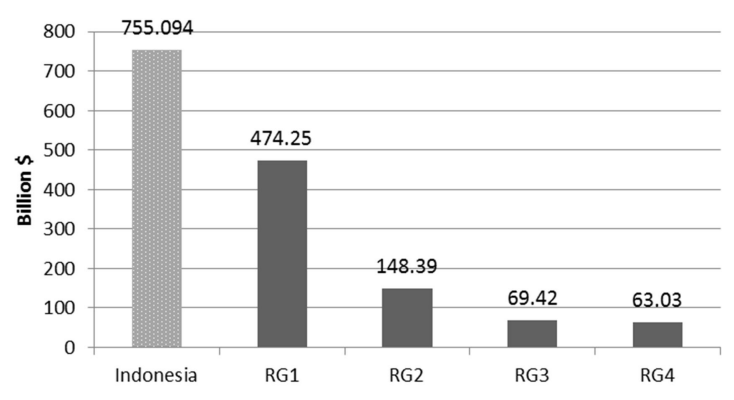

Fig. 6. GDP of Indonesia.

\section{2) Energy supply}

The data of whole Indonesia's energy supply was obtained from IEA [10], and regional energy supply data was calculated by some indexes. Industry sector (IND) and public sector (PUB) were calculated by the data of regional energy sold by type of customers from PLN Statistics 2010 [11]. Transportation sector was calculated from regional GDP ratio. The energy supply data are shown in Table I.

TABLE I: ENERGY SUPPLY DATA

\begin{tabular}{|c|c|c|c|c|c|}
\hline & & IND & PUB & TRN & ELC \\
\hline RG1 & Coal & 6.776 & 0.000 & 0.000 & 2.833 \\
\cline { 2 - 6 } & Oil & 14.728 & 6.679 & 22.483 & 2.050 \\
\cline { 2 - 6 } & Natural Gas & 12.849 & 0.132 & 0.006 & 1.943 \\
\cline { 2 - 6 } & Biomass & 5.180 & 39.180 & 0.108 & 0.000 \\
\hline RG2 & Coal & 0.893 & 0.000 & 0.000 & 0.886 \\
\cline { 2 - 6 } & Oil & 1.941 & 0.541 & 7.035 & 0.641 \\
\cline { 2 - 6 } & Natural Gas & 1.693 & 0.011 & 0.002 & 0.608 \\
\cline { 2 - 6 } & Biomass & 1.244 & 3.176 & 0.034 & 0.000 \\
\hline RG3 & Coal & 0.178 & 0.000 & 0.000 & 0.415 \\
\cline { 2 - 6 } & Oil & 0.386 & 0.155 & 3.291 & 0.300 \\
\cline { 2 - 6 } & Natural Gas & 0.337 & 0.003 & 0.001 & 0.284 \\
\cline { 2 - 6 } & Biomass & 0.582 & 0.908 & 0.016 & 0.000 \\
\hline RG4 & Coal & 0.431 & 0.000 & 0.000 & 0.377 \\
\cline { 2 - 6 } & Oil & 0.937 & 0.276 & 2.988 & 0.272 \\
\cline { 2 - 6 } & Natural Gas & 0.818 & 0.005 & 0.001 & 0.258 \\
\cline { 2 - 6 } & Biomass & 0.528 & 1.620 & 0.014 & 0.000 \\
\hline
\end{tabular}

\section{3) Energy demand and daily change}

In addition to the three sectors (industry, household transportation, and other), energy demand is also divided into the demand for electricity and those unrelated to electricity uses. Similar to energy supply data, regional energy demand data were not available. We estimated them by IEA and PLN Statistics data (Table II). $\mathrm{E}$ and $\mathrm{N}$ in the table denote electricity demand and non-electricity demand, respectively.

The main factors affecting energy demand in Indonesia are population growth and economic growth. The energy demand in 2014 was 199 TWh, more than 2.4 times that in 2000. Future energy supply is estimated to increase by an average rate of $6.2 \%$ per year through 2020 because of increased demand and improvements in the electrification rate [12]. Indonesia must make effective use of all available energy resources so that the future supply of energy is sufficient to meet the demand. Therefore, an optimal strategy is needed to support regional energy supplies in the future.

Fig. 7 shows the average daily load curves of each region. These curves show that energy demand reaches a peak from about 18:00 to 20:00. Daily load curve data were not available for Kalimantan and other islands, so in this model, Sumatra's daily load curve was adopted for Kalimantan and other islands. In the model formulation, we impose the following relationships:

\section{(Power generation of plant i at time $k) \leq$ (Power generation capacity of plant $i$ ) \\ $($ Total PowerDemand at time $k)=$ $\sum_{i}$ (Power generation of plant $i$ at time $k$ )}

Hereafter $\mathrm{DE}_{\mathrm{k}, \mathrm{t}, \mathrm{r}}$ denotes total power demand of region $\mathrm{r}$ at time $\mathrm{k}$ in period $\mathrm{t}$.

TABLE II: FINAL ENERGY DEMAND IN 2010

\begin{tabular}{|l|l|l|l|l|l|l|}
\hline \multirow{2}{*}{} & \multicolumn{3}{|c|}{ RG1 } & \multicolumn{3}{c|}{ RG2 } \\
\cline { 2 - 7 } & IND & PUB & TRN & IND & PUB & TRN \\
\hline Eletricity & 2.430 & 4.396 & 0.000 & 0.760 & 1.375 & 0.000 \\
\hline $\begin{array}{l}\text { Non- } \\
\text { Eletricity }\end{array}$ & 39.534 & 45.990 & 22.597 & 5.770 & 3.728 & 7.070 \\
\hline & \multicolumn{5}{|c|}{ RG3 } & \multicolumn{3}{c|}{ RG4 } \\
\cline { 2 - 8 } & IND & PUB & TRN & IND & PUB & TRN \\
\hline Eletricity & 0.356 & 0.643 & 0.000 & 0.323 & 0.584 & 0.000 \\
\hline $\begin{array}{l}\text { Non- } \\
\text { Eletricity }\end{array}$ & 1.483 & 1.066 & 3.308 & 2.715 & 1.902 & 3.003 \\
\hline
\end{tabular}

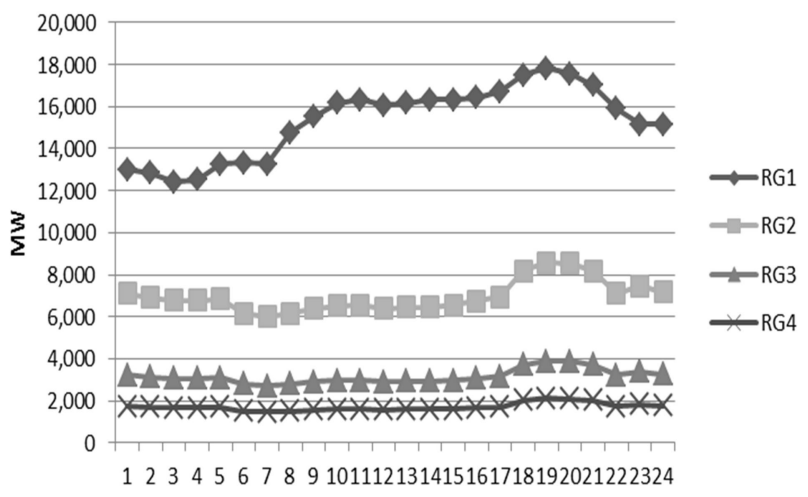

Fig. 7. Load curves of each region [13].

\section{4) Resource reserves}

Table III shows the regional coal, crude oil, and natural gas reserves data for 2012 [14]-[16]. Coal is abundant in Kalimantan and Sumatra, whereas natural gas is more prevalent in Sumatra and other islands. 
TABLE III: RESERVES IN 2012

\begin{tabular}{|l|l|l|l|}
\hline & Coal & Oil & Natural Gas \\
\hline RG1 & 0.0 & 248.2 & 250.0 \\
\hline RG2 & 19114.0 & 724.6 & 2125.0 \\
\hline RG3 & 26974.0 & 78.7 & 325.0 \\
\hline RG4 & 0.0 & 25.0 & 1050.0 \\
\hline
\end{tabular}

\section{5) Solar radiation data}

In this study, when considering the solar power generation, hourly power generation potential data per day in both dry season and rainy season. In order to estimate the power generation amount of solar power, the conversion to the inclined surface solar radiation amount which incidents on the inclined panel. Therefore, we calculate the PV power generation amount by using the solar current yield separation formula of Utagawa [17] in this study.

$$
\mathrm{PV}=\mathrm{IT} \times(1-\gamma) \times \alpha \times \beta
$$

[Explanation of variables]

PV: Estimated power generation amount $\left[\mathrm{kWh} / \mathrm{m}^{2}\right]$

IT: Solar irradiance on inclined surface of four regions in Indonesia $\left[\mathrm{kWh} / \mathrm{m}^{2}\right]$

$\gamma(=0.1)$ : Temperature loss rate

$\alpha(=0.12)$ : Conversion efficiency of a solar cell panel

$\beta$ (=1.0): Inverter conversion efficiency

Fig. 8 and Fig. 9 show the estimated output amount of solar power generation of dry season and rainy season. In this study, the dry season was defined as the seven months from May to November, and the rainy season as the five months from December to April. The highest output value in dry season is set as the $100 \%$ of output.
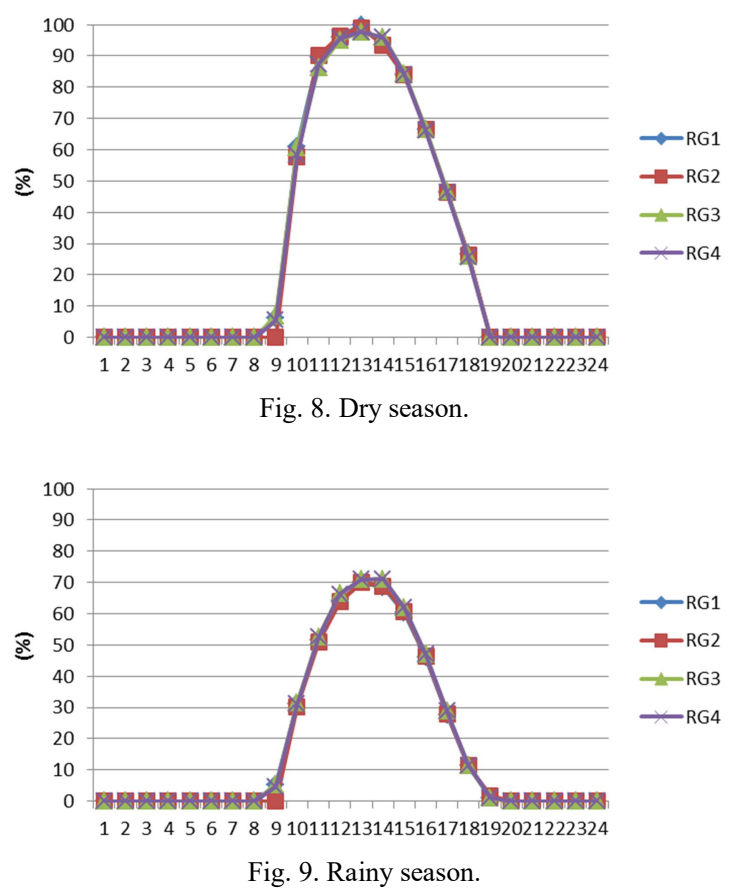

\section{Mathematical Formulation}

The simulation period started in 2010 and ran through 2045. Results are reported at 5-year intervals, beginning in 2010.

The model was formulated as an intertemporal optimization model with two-way linkages between the energy sectors and the balance of the economy. The basic formulation used to calculate energy demand is a CobbDouglas-type production function:

$$
Y_{t, r}=A_{t, r}\left[K_{t, r}^{K P V S} L_{t, r}^{(1-K P V S)}\right]^{(1-E S U B)}\left[E_{t, r}^{E L V S} N_{t, r}^{(1-E L V S)}\right]^{E S U B}
$$

where $\mathrm{Y}$ is the production function in region $\mathrm{r}$ in time period $\mathrm{t}$. $\mathrm{E}$ and $\mathrm{N}$ denote the demand for the electricity and the non-electrical energy for the industrial sector (in MTOE, million tonnes of oil equivalent). $\mathrm{L}$ is population, which is assumed to be an exogenous variable. $\mathrm{K}$ denotes capital stock and $\mathrm{A}$ is a technical progress factor.

The macroeconomic parameters were adopted from the Global 2100 model, where ESUB is the production value share of energy, and KPVS and ELVS are the capital value share parameter and the electricity value share parameter, respectively.

Energy demand in the transportation and the other sector are formulated using equation (3). The supply of energy unrelated to electricity must be adequate to cover the demand.

$$
N_{j, t, r}+\frac{E_{j, t, r}}{e f_{t, r}} \leq B_{j, r}\left(\frac{Y_{t, r}}{L_{t, r}}\right)^{\alpha} L_{t, r}
$$

where $j, \alpha$, ef and $B$ represent sector $(\mathrm{j}=$ transportation and others), a value share of income, power generation efficiency, and a constant term, respectively. Energy resource endowments are summarized in Table III. The fossil energy supply-demand balances are shown in equation (4).

As can be seen in Fig.4, primary energy source of type $m$ is distributed among energy conversion sectors including power generation. $P E_{\mathrm{m}, \mathrm{t}}$, i.e., the primary energy supply of type $\mathrm{m}$ at period $\mathrm{t}$ should hold the balance equation

$$
\sum_{t} P E_{r, m, t}-T R E_{-} D_{r, m, t}-T R E_{-} F_{r, m, t} \leq R E S_{r, m}
$$

where TRE_D and TRE_F are domestic energy and imports of total supply of primary energy $\mathrm{m}$. $\mathrm{RES}_{\mathrm{r}, \mathrm{m}}$ denotes the endowment of energy resource $\mathrm{m}$ in region $\mathrm{r}$. The total domestic transportation of energy must be balanced and is expressed as:

$$
\sum_{r} T R E_{-} D_{r, m, t}=0
$$

The gross value of production was distributed among consumption, investment for building up capital stock, and interindustry payments for energy cost (EC)

$$
Y_{t, r}=C_{t, r}+I_{t, r}+E C_{t, r}
$$

where $\mathrm{C}$ is consumption and $\mathrm{I}$ is investment. The total capital stock surviving from one period to the next was expressed as:

$$
K_{t+l, r}=(1-\delta)^{n} K_{t, r}+n \times I_{t, r}
$$

where $\delta$ is depreciation rate and $\mathrm{n}$ denotes time horizon intervals. At the end of the planning horizon, a terminal 
constraint was applied to ensure that the rate of investment is adequate.

To avoid excessively rapid expansion of new technologies, expansion rate constraints were used. The electricity energy production expansion rate constraint is expressed in equation (8) and energy rate unrelated to electricity is shown in equation (9).

$$
\begin{aligned}
& E_{t+l, r} \geq(1-\delta)^{n} E_{t, r} \\
& N_{t+l, r} \geq(1-\delta)^{n} N_{t, r}
\end{aligned}
$$

Total electric power demand $\mathrm{E}_{\mathrm{t} . \mathrm{r}}$ is then

$$
E_{t, r}=\sum_{k} D E_{k, t, r} \times \text { Days }
$$

where Days denotes the days in a year.

Equation (11) is given to promote economic independence of the region. In this equation, $\mathrm{rg}$ is the region number, Cimp and Cexp are import and export of ordinary commodity, $\mathrm{Pk}(\mathrm{T})$ is the market price of fossil fuel k, and Fimp is the net import amount of fossil fuel $\mathrm{k}$ (the negative value indicates export). This discounted present value is Dbt. That is, Dbt is the cumulative present value of the trade deficit of region $R G$ during the simulation period.

$\sum_{t}(1-d)^{t}\left\{(\operatorname{Cimp}(t, r g)-C \exp (t, r g))+\sum_{k} P_{k}(t) * \operatorname{Fimp}(t, r g, k)\right\} \leq D b t(r g)$

The model maximizes a social welfare function that is the discounted utility per capita consumption in the mathematical formulation can be expressed as:

$$
\operatorname{Max} \sum_{t, r}\left(S_{r} \times L_{t, r} \times \log \frac{C_{t, r}}{L_{t, r}} \times(1-d)^{t}\right)
$$

where $\mathrm{d}$ is the discount rate and $\mathrm{C}$ denote consumption. $\mathrm{S}$ is share of regional income per capita. In this model depreciation rate and discount rate is set to be $10 \%$ and $5 \%$ per year.

The energy sector, which includes energy production, transfer conversion, and end-use in the industrial, transportation, and other sectors, is the main contributor to anthropogenic air pollution. The main pollutants are $\mathrm{CO}_{2}, \mathrm{CO}$, particulate matter, $\mathrm{NO}_{\mathrm{x}}, \mathrm{SO}_{2}$, volatile hydrocarbons, and some heavy metals. In this study, only $\mathrm{CO}_{2}$ emissions were analyzed. $\mathrm{CO}_{2}$ emissions are associated with the consumption of coal, crude oil, and natural gas. The $\mathrm{CO}_{2}$ emissions were directly estimated when the quantity of each fuel consumption is given. $\mathrm{CF}_{\mathrm{m}}$ denotes $\mathrm{CO}_{2}$ emission coefficients for fuel $\mathrm{m}$. The total $\mathrm{CO}_{2}$ emission is calculated by:

$$
C O_{2}(t, r)=\sum_{m} P E_{r, m, t} \times C F_{m}
$$

\section{E. GAMS Software}

The model is a non-linear programming model. General Algebraic Modeling System (GAMS) software version 24.5 was used to solve the problem on a personal computer. It is generally more difficult to find the solution of a non-linear problem than that of a linear one. With a non-linear model, it is important to keep the formulation as simple as possible and the model as small as possible. Development of the model needs to be incremental so most non-linear problems can be solved more easily if some initial information is provided for the values of important variables. This process can be implemented in GAMS using initial values and bounds and by scaling variables.

\section{RESUlTS}

The simulation results by GAMS are shown in this sector. The scenarios for the simulation are two cases: the BAU case and the case of achieving the $\mathrm{CO}_{2}$ emission reduction target in INDC at the Paris Agreement (29\% reduction by 2030).

\section{A. GDP}

The result of future regional GDP of BAU case is shown in Fig. 10. The initial value is 744.09 (Billion dollars) in 2010. The result is adjusted so that the economic growth rate will be around $6 \%$.

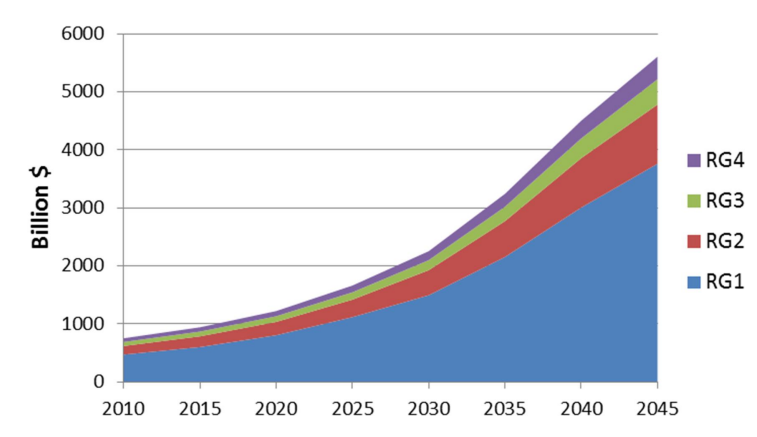

Fig. 10. GDP prediction (BAU).

\section{B. $\mathrm{CO}_{2}$ emission}

Fig. 11 shows the prediction of carbon dioxide emissions by fossil fuels in BAU case. Indonesia has the top production amount of coal in the world, and it is ranked in upper level about the amount of $\mathrm{CO}_{2}$ emissions. The emission amount rapidly increases mainly in RG1 (Java), and it increases about seven times in 2045.

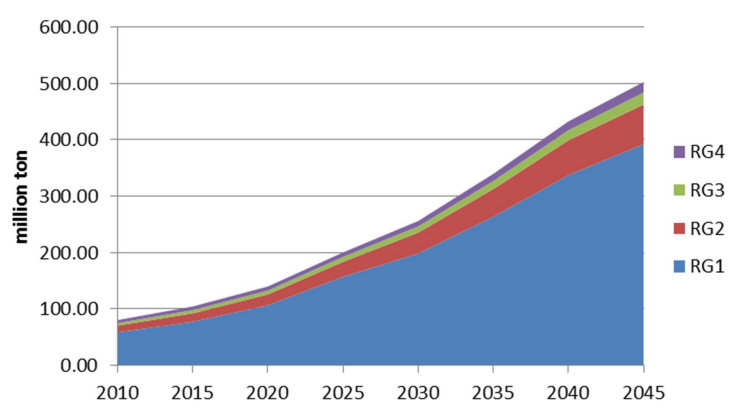

Fig. 11. $\mathrm{CO}_{2}$ emission prediction (BAU).

\section{Primary Energy Supply}

The results of energy supply amount from 2010 to 2045 are shown in from Fig. 12 to Fig. 15. It can be seen that energy supply amount will increase along with the population growth and economy growth.

Fig. 12 and Fig. 13 show the amount of energy supply to 
Java and Other Islands in the BAU case. In industry sector, coal with high reserves is the mainstay. In public and transportation sector, the use of oil is rapidly increasing. It seems that these things lead to an increase of carbon dioxide emissions. Fig. 14 and Fig. 15 show the $29 \% \mathrm{CO}_{2}$ reduction case of RG1 and RG4. The power generation configuration has changed due to reduction measure. The proportion of oil in the public sector decreases, and includes more biomass. Furthermore, the ration of geothermal power generation is larger from 2030.

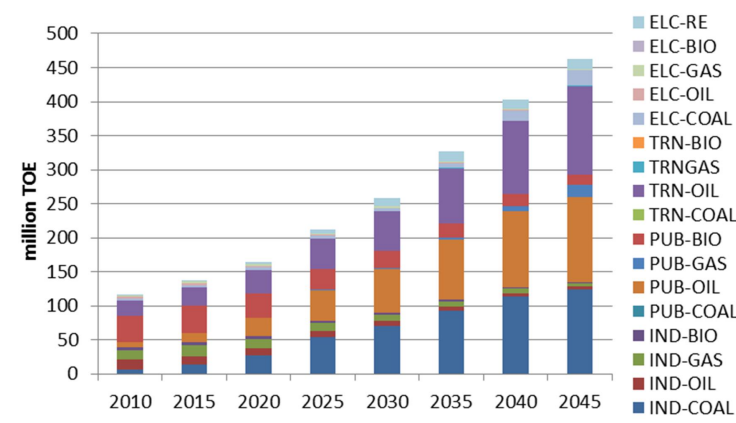

Fig. 12. Primary energy supply of RG1 (Java) BAU.

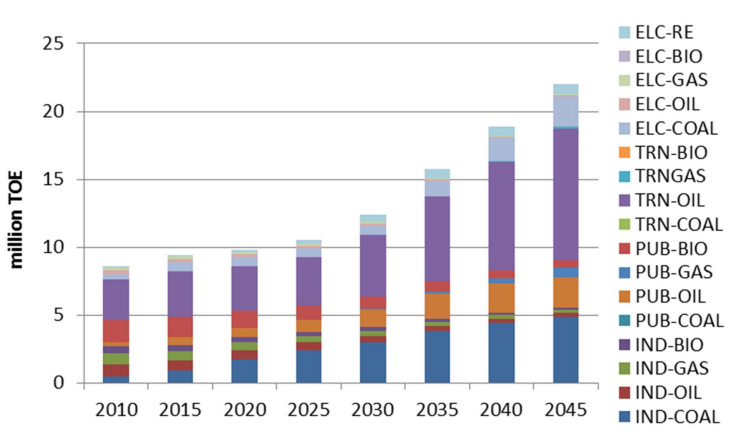

Fig. 13. Primary energy supply of RG4 (others) BAU.

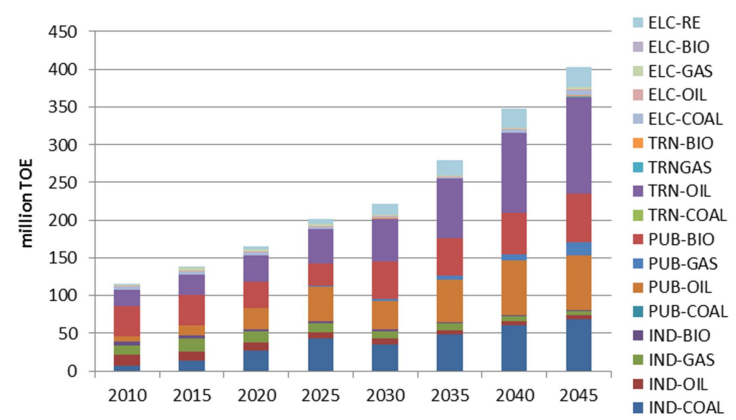

Fig. 14. Primary energy supply of RG1 (Java) $29 \%$ reduction.

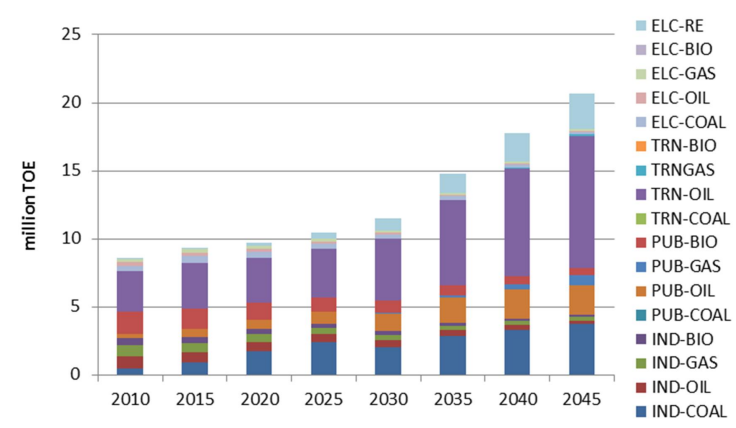

Fig. 15. Primary energy supply of RG4 (others) $29 \%$ reduction.

\section{Final Electric and Non-Electricity Energy Demand}

The results of the sectorial non-electricity demand and electricity demand from 2010 to 2045 are shown in from Fig. 16 to Fig. 19. In Java in BAU case, the energy demand increases from 114.9(million TOE) in 2010 to 461.8 (million TOE) in 2045. Especially, the demand of transportation which consumes large amount of oil is increasing. It seems that more import from other regions and countries is needed.

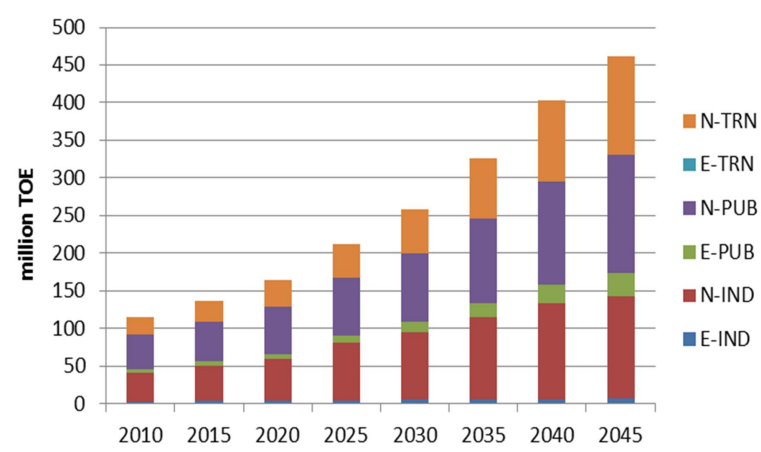

Fig. 16. Final energy demand of RG1 (Java) BAU.

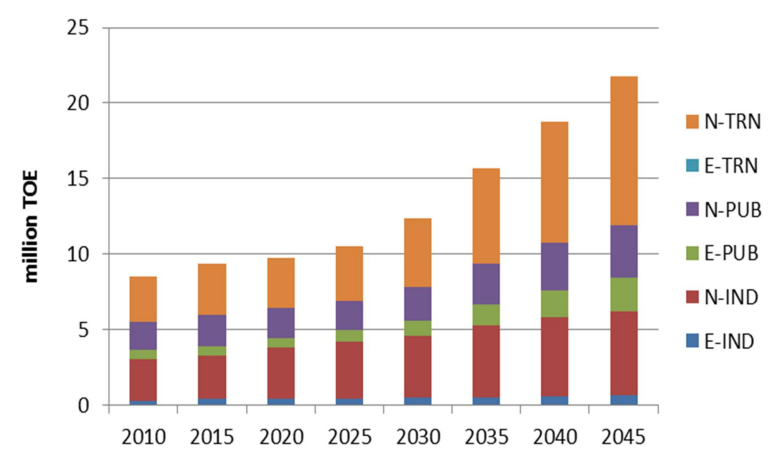

Fig. 17. Final energy demand of RG4 (others) BAU.

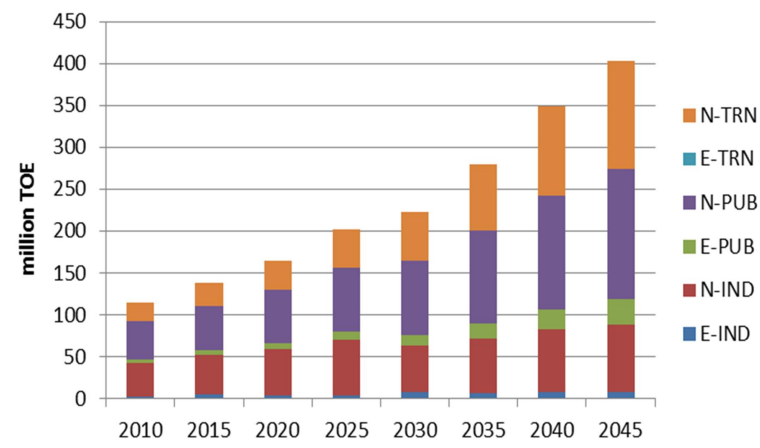

Fig. 18. Final energy demand of RG1 (Java) 29\% reduction.

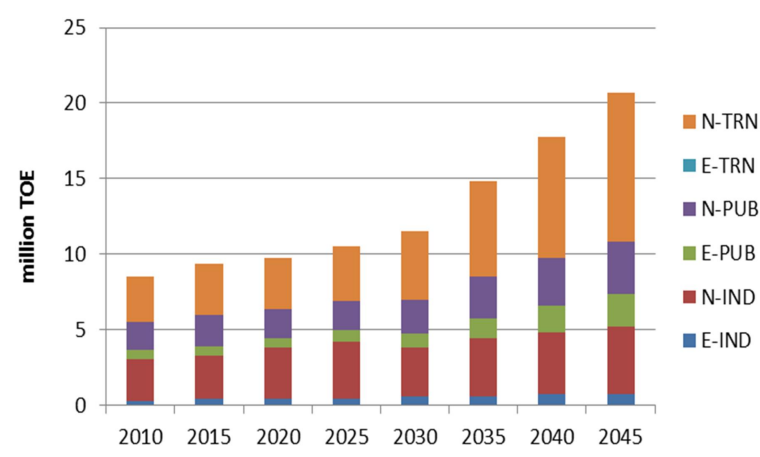

Fig. 19. Final energy demand of RG4 (others) $29 \%$ reduction.

\section{E. Net Import of Fuel and Commodity}

The net import of fuel (bar graphs) and commodity (line graphs) from 2010 to 2045 of RG1 (Java) and RG4 (others) 
are shown in from Fig. 20 to Fig. 23. Negative values in the figures represent export.

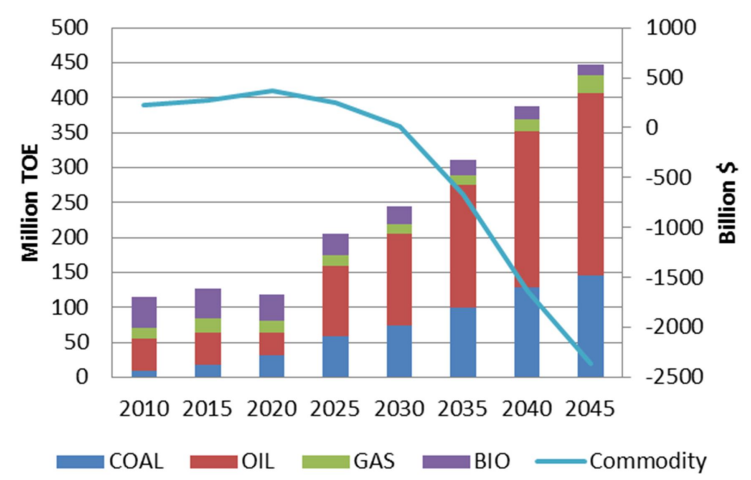

Fig. 20. Net import of fuel and commodity (RG1:Java) BAU.

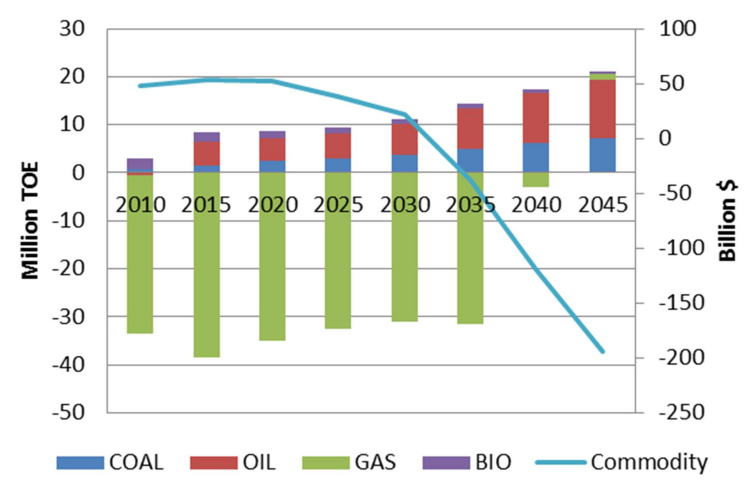

Fig. 21. Net import of fuel and commodity (RG4:others) BAU.

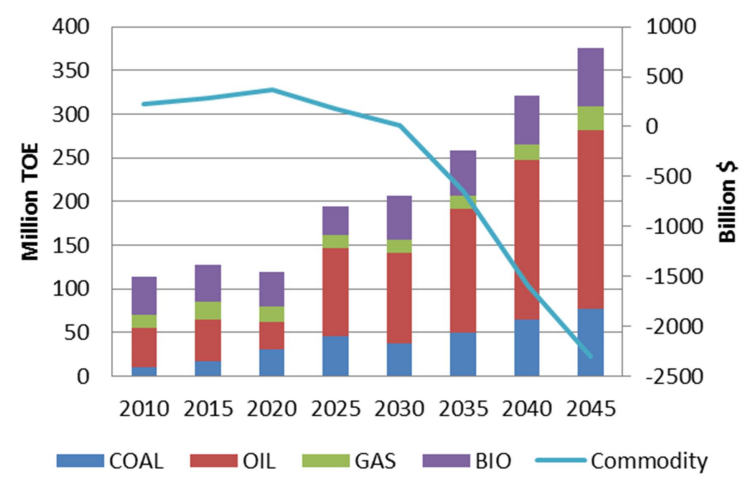

Fig. 22. Net import of fuel and commodity (RG1:Java) $29 \%$ reduction.

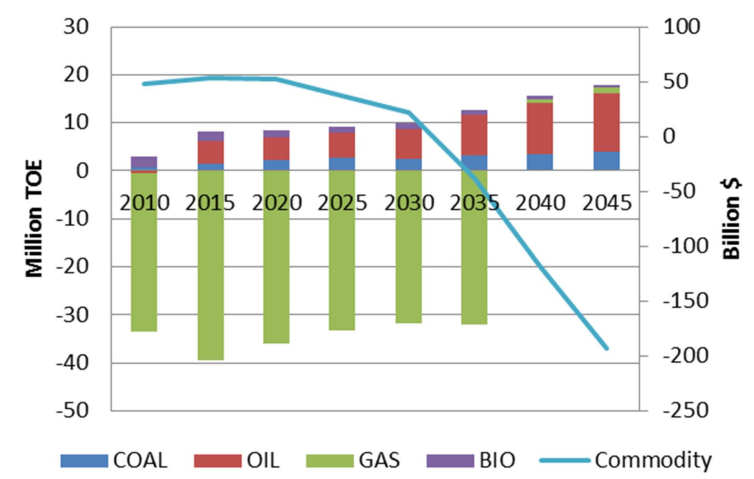

Fig. 23. Net import of fuel and commodity (RG4:others) BAU.

As for RG1, in BAU case, coal and oil will be highly imported in the future, and net import of commodity will be changed into negative value from positive value from the sixth period. In the $29 \% \mathrm{CO}_{2}$ reduction case, an import amount of biomass increases instead of coal. On the other hands, in RG4, natural gas is exported to other regions and commodity will be exported from the fifth period in both cases.

\section{CONCLUSION}

In this study, Indonesia was divided into four regions, and the regional energy use in the future was evaluated with a consideration about regional fuel transportation and daily demand change. Currently, Indonesia has a power generation structure that depends on fossil fuels, and the future carbon dioxide emissions will increase significantly in the BAU case.

In order to achieve Indonesia's reduction targets in the Paris Agreement, it is essential to use renewable energy centered on biomass and geothermal power, but in the results, although biomass was put into the power generation configuration in the $29 \% \mathrm{CO}_{2}$ reduction case, the power generation amount of other renewable energies do not achieve the goal Indonesia aims in INDC. Therefore, it can be said that further cost reduction by technological innovation or subsidy for renewable energy is necessary.

\section{REFERENCES}

[1] Intended Nationally Determined Contribution, Republic Of Indonesia, 2015.

[2] Institute for International Monetary Affairs. (January 22, 2016). Current states and notes of Indonesian Economy. Newsletter, no. 4, 2016. [Online]. Available: https://www.iima.or.jp/Docs/newsletter/2016/NL2016No_4_j.pdf

[3] R. G. Dewi, T. Kobashi, Y. Matsuoka, T. Ehara, and J. Fujino, Low Carbon Society Scenario toward 2050 Indonesia Energy Sector, Asia Pacific Integrated Model, 2010.

[4] S. Mori, "An assessment of the potentials of nuclear power and carbon capture and storage in the long-term global warming mitigation options based on Asian Modeling Exercise scenarios," Energy Economics, vol. 34, pp. S421-S428, 2012.

[5] A. Sugiyono, "An energy-economy model to evaluate the future energy demand-supply system in Indonesia," M.S. thesis, Dept. Industrial Administration, Tokyo University of Science, Japan, 1994.

[6] Statistics Indonesia. [Online]. Available: https://www.bps.go.id/linkTabelStatis/view/id/1274

[7] City $\quad$ Population. $\quad$ [Online]. https://www.citypopulation.de/Indonesia.html

[8] The World [Online]. Available: http://data.worldbank.org/country/indonesia

[9] Statista [Online]. Available: https://www.statista.com/markets/422/topic/1027/indonesia/

[10] IEA, Energy Balances, 2015.

[11] PT PLN (Persero), PLN Statistics 2010, No. 02302.110722, 2010, p. 7.

[12] Japan Industrial Trends < medium-term outlook $>$ (energy (electricity and gas)). Mizuho industry business survey 532015 No.5. [Online]. Available:

http://www.mizuhobank.co.jp/corporate/bizinfo/industry/sangyou/pd f/1053 17.pdf

[13] Indonesia PLN Jawa-Bali daily load curve. [Online]. Available: http://www.adachihayao.net/mpp3Indonesia.htm

[14] Statistic Indonesia. (2016). Badan Pusat Statistik. [Online]. Available: https://www.bps.go.id/Subjek/view/id/53\#subjekViewTab3\%7Cacco rdion-daftar-subjek3

[15] 2015 Handbook of Energy \& Economic Statistics of Indonesia, Ministry of Energy and Mineral Resources Republic of Indonesia, 2015, p. 62.

[16] Petromindo.Com, Indonesian Oil \& Gas Book 2015, pp. 509-514, 2015.

[17] M. Utagawa and K. Kimura, "Estimate of the direct solar radiation amount by the observed value of horizontal plane global solar 
radiation," Reported paper collection of Architecture Institute of Japan, no. 267, pp. 83-89, 1978.

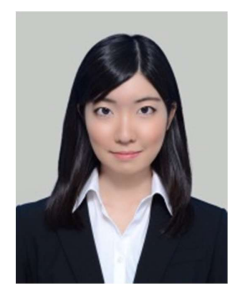

Saki Yokohama was born in Chicago, the United States in 1992.

She obtained her B.Sc. degree from Tokyo University of Science in 2015. She is currently pursuing the M.Sc. degree with Tokyo University of Science, Japan and Institut Teknologi Bandung, Indonesia.

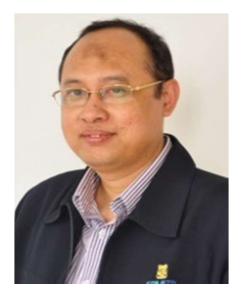

Utomo Sarjono Putro is a professor at Institut Teknologi Bandung. He received his B.Eng. from Department of Industrial Engineering, Institut Teknologi Bandung in 1992, and in 1995, he graduated from Master Program in Decision Science from Tokyo Institute of Technology, and then Doctoral Program also in Decision Science, Department of Value and Decision Science, Tokyo Institute of Technology, Japan in 2001. Prof. Utomo published his academic works in several international journals, such as IEEE Transaction on Systems, Man, and Cybernetics, and Systems Analysis Modeling Simulation, Systems Research and Behavioral Science, and Procedia Social and Behavioral Science, and as chapters in Springer Books. Starting from 2011 until now, he served as an experts in systems modelling for policy development in UKP4 (President's delivery unit for development monitoring and oversight). He is also a secretary of Indonesia National Committee for Applied Systems Analysis (INCASA) which represents Indonesia in International Institute for Applied Systems Analysis (IIASA) in Austria. Prof Utomo also active as members of International Society of for the systems science (ISSS) and Pan-Asian Association for Agent-based Approach in Social Systems Science.

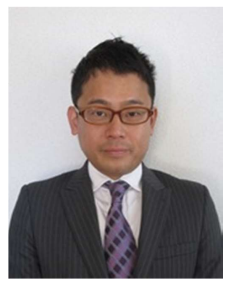

Satoshi Ohnishi was born in Tsuchiura, Japan. He is an assistant professor in the Faculty of Science and Engineering, Department of Industrial Administration in Tokyo University of Science, Japan from 2016. He had worked for National Institute of Environmental Study as a research associate during 2014-2016. He obtained a MD in the field of civil engineering from University of Tokyo and a $\mathrm{Ph}$. D. in engineering from Toyo university. His research field is industrial ecology for waste management and energy system at an urban scale.

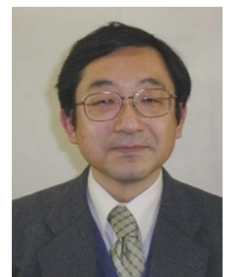

Shunsuke Mori was born in 1953. He received Doctor of Engineering from Tokyo University in 1981. Research Assistant of Industrial Administration Department, Tokyo University of Science in 1981, Associate Professor in 1989, and Professor in 1994. Dean of Graduate School of Science and Technology, Tokyo University of Science for 2012-2014. 1981-1983, Invited Researcher, Economic Planning Agency. 1986-1987, Science Researcher, International Institute for Applied Systems Analysis (Austria),1987-1993, Invited Researcher, National Institute for Science and Technology Policy. $\mathrm{He}$ is also the Chief Researcher, Research Institute of Innovative Technology for the Earth for 2002-2007. He joined the IPCC activities. Lead Author (modeling team), Special Report of Emission Scenarios, Cambridge Press, 2000, Lead Author, Third Assessment Report of IPCC, WG-III, Chapter 9, Cambridge Press, 2001, Expert Reviewer, Fourth Assessment Report of IPCC, WG-III, 2006. His field is system engineering, assessment of global warming, model development of environmental technologies. Senior member of JIE 